\title{
Knowledge, Attitudes, and Practices of Patients on COVID-19 Epidemic Attending a Primary Health Care Setting Durban, South Africa
}

\author{
A. M. Hoque, S. Buckus, M. Hoque, A. B. M. Mahbub Alam, M. E. Hoque, and N. Singh
}

\section{ABSTRACT}

There is no proven specific treatment or adequate vaccination roll out against COVID-19 infection in South Africa. Optimal infection control measures encompass primary intervention to minimize the spread of COVID-19. Public knowledge, attitude, and practices of dealing with this highly infectious respiratory disease play a vital role in limiting the spread of the infection. Aim was to identify knowledge, attitudes, and practices gaps on COVID-19 pandemic for possible health education intervention. The objectives were to determine the knowledge, attitude and practices of outpatients attending a primary health care facility. A cross-sectional descriptive survey was conducted. The Student's t-test and ANOVA test were carried out to determine the different mean scores for knowledge, attitudes and practices. Pearson's correlation test was conducted to determine the relationship between knowledge, attitudes, and practices scores. Binary logistic regression was undertaken to determine the predictor of good knowledge, positive attitude, and preventive practices. A total of 345 out-patient attendees participated of which $51 \%$ were male. Over half $(52 \%)$ of respondents were evaluated as having good knowledge, $59 \%$ as having positive attitudes and almost all $(\mathbf{9 5 \%})$ were practicing prevention of COVID-19. The knowledge of the respondent was correlated with preventive practices $(\mathrm{r}=.173, \mathrm{p}<0.05)$. Multiple regression showed that respondents in the age groups 35-44 years and 45-54 years were 2.8 times and 5.7 times more likely to have good knowledge respectively. Nonsmokers were $79 \%$ less likely to have good knowledge $(O R=.219, p<0.05)$. Respondents with no comorbidity were $50 \%$ less likely to have good knowledge $(\mathrm{OR}=.503, \mathrm{p}<\mathbf{0 . 0 5})$, when compared to those having comorbidities. Respondents with the highest level of education was found to be positive predictor of positive attitudes $(O R=7.3, p<0.05)$. Primary Health Care users have poor knowledge, negative attitudes but practiced properly for the prevention of the transmission of COVID-19. Mass education is required to educate communities to improve knowledge and attitudes on COVID-19 epidemic in SA.

Keywords: Out-patient, Kwadabeka Community Health Center, Comorbidity.

\section{INTRODUCTION}

The coronavirus disease known as the COVID-19 pandemic started in China is now a global health threat and possibly by far the largest outbreak of atypical pneumonia. [1] Human transmission has been observed via respiratory droplets and other modes causing widespread increase of patients between communities and countries [2] Transmissibility of COVID-19 in South Africa (SA) as indicated by its reproductive number has been estimated at 2.95, suggesting that on average, every case of COVID-19 will infect up to three new cases [3]. The estimated average incubation period for the virus is measured to be 5.2 days, but with variation among patients and its capacity to asymptomatic spread [4]-[6]. The symptoms of infection which are important include fever, chills, cough, anosmia, sore throat, breathing difficulty, myalgia, nausea, vomiting,
Submitted : March 6, 2021

Published : March 27, 2021

ISSN: 2593-8339

DOI: $10.24018 /$ ejmed.2021.3.2.758

A. M. Hoque *

Kwadabeka Community Health Centre, Durban, South Africa.

(e-mail: mhoque75@gmail.com)

S. Buckus

Kwadabeka Community Health Centre, Durban, South Africa.

M. Hoque

South African College of Applied Psychology, Durban, South Africa. Dr A. B. M. Mahbub Alam

National Institute of Kidney Diseases and Urology, Bangladesh.

M. E. Hoque

Management College of Southern Africa, Durban, South Africa.

Prof N. Singh, PhD

School of Life Sciences, University of Kwa-Zulu Natal, Durban, South Africa.

*Corresponding Author diarrhoea, and others yet to be confirmed [7]. Older people (age $\geq 50$ years) with medical and surgical co-morbidities are reported to be more prone to the infection, and with greater severity [7]. Severe cases of COVID-19 are known to lead to cardiac injury, respiratory failure, and death [8]. The provisional case fatality rate as reported by the WHO is approximately $2 \%$, although higher rates in the vicinity of $2.2 \%$ have been reported from SA and other countries [3], [9], [10].

The COVID-19 outbreak has a significant impact on the lifestyle of the general population of SA and all other countries directly or indirectly. The National government of SA has taken commendable interventions to combat the spread of the COVID-19 pandemic based on the WHO recommendations. These included the national lock down, the suspension of public transportation, banning of international travel, closing of public places, close monitoring and 
management of communities and isolated care for infected people and suspected cases. As the pandemic started to spread to different parts of the country, the national government implemented lockdown of the entire country from 27 March to 30 September 2020 whereby social interaction was prohibited.

Currently there is no proven specific treatment or vaccination roll out against COVID-19 infection in SA. Optimal infection control measures are the primary interventions to minimize the spread of the virus in both health care settings and in the communities [11]. Public awareness of dealing with this highly infectious respiratory disease plays a vital role in limiting the spread of the infection, especially in middle- and low-income countries. As of 17 February 2021, the novel coronavirus has infected over 1.5 million people with 48940 deaths [12]. Whilst waiting for vaccination roll out the management of the epidemic depends primarily on people's adherence to the recommended universal preventive measures taken and these measures are largely affected by knowledge, attitudes, and practices (KAP) of the people [13]. To date most of the reports published on KAP of COVID-19 are based on on-line or phone call surveys and thus these surveys are not relevant in African or SA settings [14], [15].

To guarantee the final success, people's adherence to the prevention measures are essential, which is largely affected and influenced by their KAP towards COVID-19 in accordance with KAP theory [16], [17]. However, there is no research investigating the KAP of COVID-19 on the general population in SA. To make contribution for optimal COVID19 outbreak management in SA, there is an urgent need to understand the awareness of the general population on COVID-19. Therefore, the objective of this study was to determine the knowledge, attitudes and practices of the patients attending a primary health care setting in Durban, South Africa.

\section{MATERIAL AND METHOD}

\section{A. Study Design}

A cross-sectional descriptive survey was conducted at Kwadabeka Community Health Center (KCHC), Durban during the COVID-19 epidemic in SA between 1 and 30 September 2020.

\section{B. Setting and Subjects}

$\mathrm{KCHC}$ is situated in the communities of Kwadabeka and Clermont townships with residence of over 133000 black residents. Most of whom are reliant on $\mathrm{KCHC}$ as the first contact to public health facility. It provides comprehensive Primary Health Care (PHC) service package to its clients free of charge. The services include acute and chronic types of illnesses, male, female, adult, children, and pregnant women. There are over 20, 000 headcounts at KCHC every month. It is situated about $35 \mathrm{~km}$ north-west suburb of eThekwini (Durban) Metropolitan city. All residences are black homogenous Africans and living in formal and informal (mainly) dwellings.

\section{Sample Size, Selection and Data Collection}

The determination of the sample size was undertaken using the Epi Info 7 software. As there were no similar studies related to COVID-19 epidemic in SA, the calculation was based on the assumption that the probability of having good knowledge on, positive attitude towards and COVID-19 preventive measures were $50.0 \%$, at $95 \%$ confidence interval, $5 \%$ limit of precision and a design effect of 1.0.

Data was collected from adults (age $>18$ years) male and female attendees from the adult out-patients consulting rooms by the Medical Officers (including the investigators of the study) using a structured questionnaire both in English and isiZulu the local language, which ever was possible. The respondent was attending for any medical condition without the symptoms of COVID-19 infection. The suspected cases of COVID-19 were isolated at the triage area of the facility. The questionnaire was developed by the researchers based on published reports and dealt with demographics, knowledge, attitude. and practices of preventative health behavior of COVID-19. [18], [19] The study samples were selected from the patients attending KCHC outpatient departments. All patients who attended the doctor's consultation were asked to participate in the study after the consultation.

\section{Questionnaire}

There were thirteen, five and six questions those were asked to determine participant's knowledge, attitudes and practices respectively regarding COVID-19. All the questions are dealt with in later sections.

\section{E. Measurements}

Each correct answer by the participant for a question earned a score of ' 1 ' and each incorrect answer earned a score of ' 0 '. Knowledge, attitudes, and practices were measured by adding the scores for the correct and incorrect answers or positive or negative statements. Scoring above 50\% was considered good knowledge, positive attitudes, and good practices towards COVID-19.

\section{F. Data Analysis}

Data were coded, captured, and analysed using SPSS version 22. Descriptive statistics such as mean with standard deviation (SD) for continuous variables and frequency distribution for categorical variables were reported. Student's t-test and ANOVA test were carried out to find different mean scores for KAP. Pearson's correlation test was conducted to determine the relationship between knowledge, attitudes, and practices scores. Binary logistic regression analysis was undertaken to determine the predictor of good knowledge, positive attitudes, and preventive practices. The results were presented with Odds Ratio (OR) with 95\% confidence interval (CI). P-values $<0.05$ was considered statistically significant.

\section{G. Ethical Consideration}

Ethical approval was obtained from Umgungundlovu Health Ethics Research Board (reference: UHERB 06/2020). Anonymity and confidentiality of the respondent were maintained at all times. Participation in the study was voluntary. Data was collected after obtaining informed consent from the participants. 


\section{RESULTS}

Demographic, personal and household $(\mathrm{HH})$ risk factors can be seen in Table I. A total of 345 outpatient attendees participated in the study and male represented the most $(51.4 \%)$. Most of the respondents were single (64.2\%), age between $25-44$ years (52\%), unemployed (55\%) and low level of education (only 14\% had matric qualification). Only $3 \%$ of the respondents were found to drink alcohol during the epidemic, but this rate was higher $(17.5 \%)$ before the epidemic (regular drinker). Smoking habit was found among $10.5 \%$ during the epidemic which reduced from $14.3 \%$ before the epidemic. More than half $(51.5 \%)$ of the respondents were found with vulnerable medical comorbidity. Among the comorbidities, HIV infection (27\%) was the commonest followed by hypertension (18\%) and diabetes (13.6\%) (data not shown).

TABLE I: DEMOgRAPHIC, PERSONAL BEHAVIOR AND HOUSEHOLD RisK

\begin{tabular}{|c|c|c|}
\hline Variables & Frequency & Percentage \\
\hline \multicolumn{3}{|l|}{ Gender $(n=343)$} \\
\hline Male & 168 & 49.0 \\
\hline Female & 175 & 51.0 \\
\hline \multicolumn{3}{|l|}{ Marital status $(n=340)$} \\
\hline Single & 218 & 64.1 \\
\hline Married & 86 & 25.3 \\
\hline Living together & 24 & 7.1 \\
\hline Widow & 12 & 3.5 \\
\hline \multicolumn{3}{|l|}{ Age $(n=326)$} \\
\hline$<25$ years & 47 & 14.4 \\
\hline $25-34$ years & 103 & 31.6 \\
\hline 35 to 44 years & 67 & 20.6 \\
\hline 45 to 54 years & 41 & 12.5 \\
\hline 55 years and above & 68 & 20.9 \\
\hline \multicolumn{3}{|l|}{ Employment status $(\mathrm{n}=334)$} \\
\hline Full- time & 99 & 29.6 \\
\hline Part- time & 49 & 14.2 \\
\hline Unemployment & 186 & 55.7 \\
\hline \multicolumn{3}{|l|}{ Education level $(\mathrm{n}=341)$} \\
\hline No education & 17 & 5 \\
\hline 1- 5 years schooling & 29 & 8.5 \\
\hline $6-11$ years of schooling & 116 & 34 \\
\hline Completed Matric & 131 & 38.4 \\
\hline $\begin{array}{l}\text { Post matric/ Higher } \\
\text { education }\end{array}$ & 48 & 14.1 \\
\hline \multicolumn{3}{|l|}{$\begin{array}{l}\text { Personal and household risk } \\
\text { factors }\end{array}$} \\
\hline Presence of co-morbidities & 167 & 54.2 \\
\hline $\begin{array}{l}\text { Drink alcohol regularly } \\
(n=344)\end{array}$ & 59 & 17.5 \\
\hline $\begin{array}{l}\text { Drink alcohol during the } \\
\text { epidemic (344) }\end{array}$ & 9 & 2.8 \\
\hline Usual smokers $(n=344)$ & 49 & 14.3 \\
\hline $\begin{array}{l}\text { Smoke tobacco during the } \\
\text { epidemic }(n=344)\end{array}$ & 33 & 10.5 \\
\hline
\end{tabular}

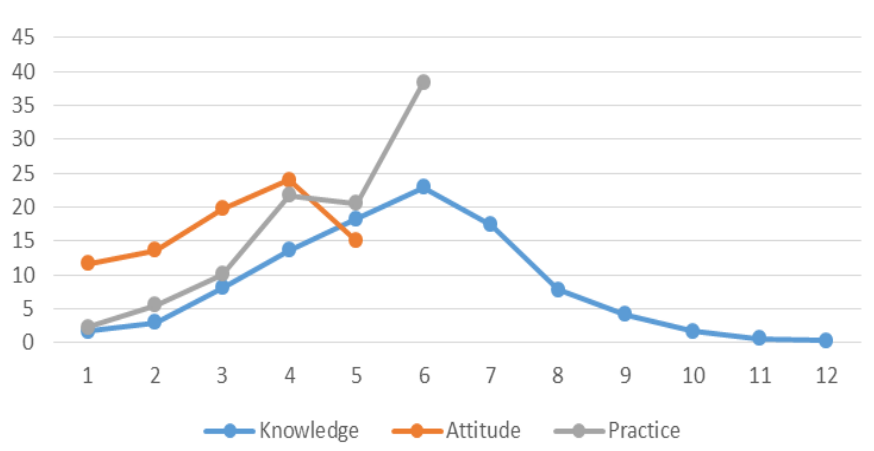

Fig. 1. Total KAP score distribution of respondents.
The KAP scores of the respondents are presented in Fig. 1. On assessing the knowledge of COVID-19, the mean knowledge was $5.6(\mathrm{SD}=1.95)$ out of a total of 13 points translated to $43 \%$. Only half $(52.2 \%)$ of respondents were found with good knowledge. The most known symptoms were cough $(62.8 \%)$, difficulty in breathing $(50.1 \%)$ followed by fever $(40.5 \%)$. Only $20.2 \%$ of patients identified sore throat as a symptom of COVID-19. Only a few participants (10.4\%) knew loss of smell and body pain $(9.0 \%)$ as symptoms. Majority of the respondents $(78.9 \%)$ had good knowledge on; "smokers who get COVID-19 are more likely to get ill than non-smokers". More than two thirds $(68.5 \%)$ of them knew that "most people who get COVID-19 do not become very ill". Just under two thirds (62.4\%) of study subjects agreed with "one can be infected with the virus without any symptoms". Just over half (53.7\% and 50.2\%) knew that "children get less ill from the virus than adults" and "not only the elderly would die from COVID-19" respectively. The findings of this study demonstrated poor knowledge on the survival of the virus for days outside the body on plastic surfaces (45\%) and that the virus can survive outside the body for up to 7 days $(39.8 \%)$.

The mean score for attitudes was $2.7(\mathrm{SD}=1.67)$ out of a total of 5 that translates to $54 \%$. The positive attitudes (> $50 \%$ ) were found among $58.6 \%$ of the respondents. The majority $(70.6 \%)$ of the subjects did not think that COVID19 would cause a serious infection. Just under two thirds $(63.1 \%)$ were confident that the health facility can handle the COVID-19 pandemic and $61.9 \%$ think that they might get infection with the virus. Under half $(48.3 \%)$ of them thought that the South African Government would be able to handle the epidemic whilst only $26.5 \%$ thought that the $\mathrm{KCHC}$ would have sufficient medical supplies to handle the epidemic.

The respondents of this study practiced preventive behavior with a mean practice score of $5(\mathrm{SD}=1.2)$ out of a total of 6 points translated to $83.3 \%$. Nearly all (95.4\%) were practicing preventive practices. The majority (93\%) of the respondents would not visit a friend or a relative who would be COVID-19 positive, $86.5 \%$ would not visit a family or a friend during the COVID-19 epidemic, $85 \%$ would wash or sanitize their hands when coming home from outside, $81.8 \%$ used a face mask in public places, $79.7 \%$ were maintaining social distance in public places and $79.1 \%$ were covering their mouths when sneezing or coughing.

Table II depicted the relationship between KAP scores and showed that knowledge was fairly positively correlated with practice $(\mathrm{r}=0.173, \mathrm{p}<0.05)$. Attitude had no significant correlation with knowledge and practice scores ( $p>0.05)$.

When comparing the overall knowledge, attitudes and practice scores related to demographic variables using the students t-test and ANOVA test, it was found that the mean knowledge score was significantly higher as the ages of the respondents were increased $(\mathrm{p}<0.05)$ (Table III). Unemployed respondents were shown to have significantly higher mean knowledge score $(\mathrm{p}<0.05)$.

Smokers had a significantly higher mean knowledge score than non-smokers $(p<0.05)$. Gender and the presence of vulnerable comorbidity were related to significant practice mean differences. Males had significantly higher mean preventive practice score than females $(\mathrm{p}<0.05)$. Respondents 
with comorbidities were found with significantly higher mean practice score $(\mathrm{p}<0.05)$ and higher (positive) attitude mean $(\mathrm{p}<0.05)$ towards COVID-19 epidemic.

TABLE II: PEARSON CORRELATION OUTCOME AMONG FinAl SCORES OF KAP OF THE RESPONDENTS

\begin{tabular}{|c|c|c|c|c|}
\hline & & Total attitude & $\begin{array}{c}\text { Final } \\
\text { knowledge } \\
\text { score }\end{array}$ & $\begin{array}{c}\text { Final Score } \\
\text { Practice }\end{array}$ \\
\hline \multirow{3}{*}{$\begin{array}{c}\text { Total } \\
\text { attitude }\end{array}$} & $\begin{array}{c}\text { Pearson } \\
\text { Correlation }\end{array}$ & 1 & .047 & .072 \\
\hline & Sig. (2-tailed) & & .388 & .183 \\
\hline & $\mathrm{N}$ & 345 & 345 & 345 \\
\hline \multirow{3}{*}{$\begin{array}{c}\text { Final } \\
\text { knowledge } \\
\text { score }\end{array}$} & $\begin{array}{c}\text { Pearson } \\
\text { Correlation }\end{array}$ & .047 & 1 & $.173^{* *}$ \\
\hline & Sig. (2-tailed) & .388 & & .001 \\
\hline & $\mathrm{N}$ & 345 & 345 & 345 \\
\hline \multirow{3}{*}{$\begin{array}{l}\text { Final Score } \\
\text { Practice }\end{array}$} & $\begin{array}{c}\text { Pearson } \\
\text { Correlation }\end{array}$ & .072 & $.173^{* *}$ & 1 \\
\hline & Sig. (2-tailed) & .183 & .001 & \\
\hline & $\mathrm{N}$ & 345 & 345 & 345 \\
\hline
\end{tabular}

**. Correlation is significant at the 0.01 level (2-tailed).

TABLE III: COMPARISON OF THE MEAN KNOWLEDGE, ATTITUDE AND PRACTICE WITH REGARDS TO DEMOGRAPHIC VARIABLES OF THE RESPONDENTS USING T- TEST ANOVA TEST

\begin{tabular}{|c|c|c|c|c|}
\hline \multicolumn{2}{|c|}{ Variables } & $\mathrm{N}$ & Mean & $\mathrm{P}$-value \\
\hline \multicolumn{5}{|c|}{ Knowledge } \\
\hline \multirow{5}{*}{ Age } & $<25$ years & 47 & 2.87 & \multirow{5}{*}{0.001} \\
\hline & $25-34$ years & 103 & 3.74 & \\
\hline & 35 to 44 years & 67 & 3.71 & \\
\hline & 45 to 54 years & 41 & 3.56 & \\
\hline & 55 years and above & 68 & 3.14 & \\
\hline \multirow{3}{*}{$\begin{array}{l}\text { Employment } \\
\text { status }\end{array}$} & Full- time & 99 & 2.49 & \multirow{3}{*}{0.011} \\
\hline & Part- time & 49 & 2.47 & \\
\hline & Unemployment & 186 & 2.81 & \\
\hline \multirow{2}{*}{$\begin{array}{c}\text { Smoking during } \\
\text { pandemic }\end{array}$} & No & 282 & 3.43 & \multirow{2}{*}{0.010} \\
\hline & Yes & 33 & 4.09 & \\
\hline \multicolumn{5}{|c|}{ Practice } \\
\hline \multirow{2}{*}{ Gender } & Male & 168 & 2.85 & \multirow{2}{*}{0.032} \\
\hline & Female & 175 & 2.51 & \\
\hline \multirow{2}{*}{ Comorbidity } & None & 158 & 4.77 & \multirow{2}{*}{0.005} \\
\hline & Present & 186 & 5.17 & \\
\hline \multicolumn{5}{|c|}{ Attitude } \\
\hline Comorbidity & None & 158 & 2.42 & \multirow{2}{*}{0.007} \\
\hline & Present & 186 & 2.91 & \\
\hline
\end{tabular}

Multiple regression analysis output showed that respondents of older ages (35-44 years and 45-54 years) were 2.8 times and 5.7 times more likely to have good knowledge $(\mathrm{OR}=2.8,95 \% \mathrm{CI} ; 1.2: 6.7, \mathrm{p}<0.05$ and $\mathrm{OR}=5.7,95 \% \mathrm{CI}$; 2.0:16.4, $\mathrm{p}<0.05$ ) respectively (Table IV).

TABLE IV: BINARY LOGISTIC ANALYSIS OUTPUT FOR GOOD KNOWLEDGE OF THE RESPONDENTS

\begin{tabular}{ccccc}
\hline & OF THE RESPONDENTS & & \\
Variables & \multirow{2}{*}{ Sig. } & Odds Ratio & \multicolumn{2}{c}{ 95\% C.I for OR } \\
\cline { 5 - 6 } & & (OR) & Lower & Upper \\
\hline Age category & .005 & & & \\
Age < 25 years & .478 & 1.499 & .490 & 4.583 \\
Age 25-34 years & .553 & 1.279 & .567 & 2.884 \\
Age 35-44 years & .015 & 2.872 & 1.224 & 6.738 \\
Age 45-54 years & .001 & 5.730 & 2.001 & 16.408 \\
Currently not smoking tobacco & .003 & .219 & .081 & .593 \\
Absence of co-morbidity & .031 & .503 & .269 & .940 \\
Constant & .021 & 3.206 & & \\
\hline
\end{tabular}

Non-smokers were $79 \%$ less likely to have good knowledge as $\mathrm{OR}=.219,95 \% \mathrm{CI} ; .081: .593, \mathrm{p}<0.05$. Respondents with no comorbidity were $50 \%$ less likely to have good knowledge $(\mathrm{OR}=.503,95 \% \mathrm{CI} ; .26: .94, \mathrm{p}<0.05)$. Respondent with no education was found to be 7 times more likely to have negative attitudes towards COVID-19 epidemic (OR =7.3, 95\% CI; 1.2:42.8, p <0.05)
(Table V). There was no demographic variable found as a predictor of good practice (data not shown).

\begin{tabular}{|c|c|c|c|c|}
\hline \multirow{2}{*}{ Variables } & \multirow{2}{*}{ Sig. } & \multirow{2}{*}{$\begin{array}{l}\text { Odds Ratio } \\
(\mathrm{OR})\end{array}$} & \multicolumn{2}{|c|}{$95 \%$ C.I. for OR } \\
\hline & & & Lower & Upper \\
\hline Level of education & .112 & & & \\
\hline No education & .026 & 7.39 & 1.27 & 42.86 \\
\hline $1-5$ years schooling & .361 & 1.70 & .54 & 5.32 \\
\hline 6-11 years schooling & .252 & 1.70 & .68 & 4.26 \\
\hline $\begin{array}{l}12 \text { years Matric } \\
\text { completed }\end{array}$ & .931 & 1.04 & .42 & 2.51 \\
\hline $\begin{array}{c}\text { Currently smoke tobacco } \\
\text { (1) }\end{array}$ & .094 & 2.18 & .87 & 5.48 \\
\hline Constant & .238 & .51 & & \\
\hline
\end{tabular}

\section{DISCUSSION}

This study provides an insight on the level of personal knowledge, attitudes, and preventive practices to deal with coronavirus infection, transmission and prevention among the general people attending $\mathrm{KCHC}$ at the time of the COVID-19 pandemic and national lockdown in SA. To date, there has been limited published data on the KAP of the general population towards COVID-19 in SA. This study is unique because it was undertaken in a PHC facility in SA to describe the KAP gap to identify and implement programs to better protect the communities of rural areas.

The demographic indicators such as low level of education and being unemployed $(54.5 \%)$ reflect poor socioeconomic status. More than half $(51.5 \%)$ of the participants had vulnerable comorbidities for COVID-19. According to the reported data, it is indicated that HIV and hypertension are the most common comorbidities in SA [3]. Therefore, utmost care and protection must be provided for these vulnerable groups, at home and when they attend KCHC. Strategies undertaken at $\mathrm{KCHC}$ include the dispensing of medication for a period of 3 months, rather than one, which was the norm. Furthermore, a priority queue was introduced during the epidemic period by the directive of National and provincial health authorities to render a faster service.

A good percentage (84\%) of the respondents had reduced alcohol consumption from $17.2 \%$ (before the epidemic) to $2.8 \%$ during the epidemic, and this may be attributed to the ban on the sale of alcohol and tobacco during the national lockdown in SA. Similarly, a moderate reduction of $26 \%$ of smoking from $14.3 \%$ to $10.5 \%$ was found among these respondents. [16]. However, the reduction of smoking behavior may not have been as desired, as it was reported that cigarettes were still available due to the illegal trading during the ban [20]. Importantly, cigarette smokers are rendered vulnerable and at a higher risk for COVID-19.

In the absence of a COVID-19 vaccine, preventive measures play an integral role in reducing person-to-person transmission thereby controlling the spread of the disease in the general population [21]. The pandemic poses a major health problem to the population at large, with higher mortality and morbidity in the vulnerable groups, and this includes people with existing comorbidities. Adequate knowledge is regarded as being crucial for the better establishment of preventive belief and for the development of positive attitudes and practices whilst inadequate knowledge poses a higher risk of infection [22], [23]. 
The present study found poor level of knowledge about COVID-19 among the PHC attendees from a community in SA. Higher levels of knowledge regarding COVID-19 were found in studies conducted in other parts of Africa. For example, a study of PHC facility users from Nigeria reported a higher level of knowledge. [24] Another study conducted in Ethiopia among the general population found higher levels of knowledge about COVID-19 [25]. The poor knowledge of our populations on COVID-19 among the participant from a rural poor socio-economic condition is expected, because this epidemiological survey was conducted during the early stages of the epidemic in SA and amongst respondents who had a low level of education (only $14 \%$ had tertiary education) compared to the subjects of Nigerian study (54\%) [24]. These factors are known to hinder the gaining of proper and adequate knowledge [26]. Education, age, and income had been documented to be highly relevant to knowledge [21]. The difference could also partly be attributed to the timing of our study, as this study was undertaken during the early stages of the COVID-19 epidemic SA, where difficulty in accessing and obtaining true and timeous information was probable and differences in demographic and socio-economic status.

About a third of the participants in this study knew that COVID-19 infection does not make someone very sick and only $41.5 \%$ knew about the survival of the virus outside the body. The findings in our study indicate that most of the participants had extremely poor knowledge on the survival of the virus. During this early stage of the pandemic in SA, enough knowledge on the symptoms of COVID-19 were readily available, but little was known to the general population of the survival and transmission of the virus.

The present study found that most of the participants had good attitudes towards COVID-19. It was very surprising to see that $27 \%$ of the participants thought that $\mathrm{KCHC}$ would have adequate medical supplies to handle the epidemic and less than half believed that SA Government can handle the COVID-19 pandemic. The lack of trust in the South African government and healthcare facilities could be a result of anxiety within the general population. There is a possibility that a substantial proportion of the general population become anxious and paranoid during a pandemic. Stress, rumors, and exhaustion of available resources occur with further misconceptions in the media and social platforms which contributes to the negative attitudes experienced by the general population in South Africa [27].

In this study, no significant relationship was found between knowledge and attitudes regarding COVID-19. This finding is not consistent with findings in other studies on KAP of COVID-19 in other parts of Africa and internationally where a significant relationship between knowledge and attitude towards COVID-19 exists amongst the general population [28]-[31]. This could be probable due to the implementation of regulation such as the national lockdown which lead to home quarantine, banning on sale of alcohol and tobacco products, and social distancing.

Preventive practices towards COVID-19 were found to be good among the participants. This was possible as stricter rules and regulations were imposed, implemented, and monitored by the Government of SA. The wearing of face masks, social distancing and washing of hands with sanitizer became mandatory at all public places and were monitored by the SA government agencies.

Smokers had better mean knowledge of COVID-19 than non-smokers. There are numerous research reports described the adverse consequences of COVID-19 on the health of people who smoke. A survey conducted in Cape Town, SA [16] showed that cigarettes were still very accessible to the public. A possible explanation for smokers having a higher mean knowledge than people who do not smoke could be that such individuals who continued to smoke during the lockdown when cigarettes were banned wanted to educate themselves to prevent the risk of infection and transmission of COVID-19.

Our findings showed that the mean knowledge of COVID19 increased with age. This finding is consistent with findings in other studies conducted in China [21], [32]. It might be due to the reason that older people are at higher risk for complications of COVID-19 and hence familiarize and educate themselves more on the disease. Mean knowledge was also higher in unemployed people. Another possible explanation could be that those individuals who are unemployed had more time to spare and acquire knowledge on COVID-19 via television, newspapers, and other media platforms. A similar trend of knowledge was reported elsewhere [33] which showed that knowledge of COVID-19 was high in a low income setting where majority of participants were unemployed.

Furthermore, our findings in this study indicate that patients with no education were seven times more likely to have a negative attitude towards COVID-19. This is consistent and comparable with other studies in abroad which revealed that those that attained higher education were significantly more likely to have positive attitudes, and preventive practice towards COVID-19 [24], [25].

The findings from this study are useful for public health policymakers and health workers to recognize target population for COVID-19 prevention and health education. These findings further suggest that the health education intervention would be more effective if it targets the identified demographic, geographic groups. The implementation of national regulations ensuring positive practices of people also found to work positively for prevention of epidemic, for example, the COVID-19 knowledge may be greatly increased if the health education programs are specifically designed.

\section{CONCLUSION}

The results revealed that patients at public primary healthcare facilities from a rural black community, demonstrated poor knowledge, positive attitude, and very good preventive practices about COVID-19. Participants with higher level of education were found with positive attitudes. Based on these findings, we recommend public health education programs on COVID-19 should be targeted at individuals with low knowledge level, lower educational attainment, and that more efforts are needed for residents of the Kwadabeka and similar rural communities of SA. Implementation of national regulations towards healthy practices may enhance the right attitude and the adoption of 
unharmful COVID-19 related practices which are necessary mitigating the impact of COVID-19 on the target population.

\section{ACKNOWLEDGMENT}

We thank all the participants who voluntarily took part in this study, the two Medical officers (Dr V. Mkosana, and Dr S. Lamula) who assisted in data collection.

\section{REFERENCES}

[1] Wang, C. A novel coronavirus outbreak of global health concern. Lancet 2020, 395, 470-473.

[2] World Health Organization. Coronavirus disease 2019 (COVID-19) situation report-78. 2020. Reference Source.

[3] Mukandavire Z, Nyabadza F, Malunguza NJ, Cuadros DF et al. Quantifying early COVID-19 outbreak transmission in South Africa and exploring vaccine efficacy scenarios. PloS one. 2020; 15(7):236243.

[4] Li Q, Guan X, Wu P, Wang X, Zhou L, Tong Y, Ren R et al. Early transmission dynamics in Wuhan, China, of novel coronavirusinfected pneumonia. N Engl J Med 2020; 382:1199-1207.

[5] Rothe C, Schunk M, Sothmann P, Bretzel G, Froeschl G et al. Transmission of 2019-nCoV infection from an asymptomatic contact in Germany. N Engl J Med 2020; 382(10):970-1.

[6] Ryu S, Chun BC. Korean Society of Epidemiology-nCo, an interim review of the epidemiological characteristics of 2019 novel coronavirus. Epidemiol. Health 2020, 42.

[7] Chen, N. Epidemiological and clinical characteristics of 99 cases of 2019 novel coronavirus pneumonia in Wuhan, China: A descriptive study. Lancet 2020, 395, 507-513.

[8] Holshue ML, DeBolt C, Lindquist S, Lofy KH, Wiesman J et al. First case of 2019 novel coronavirus in the United States. N Engl J Med. 2020; 382:929-936.

[9] Austrian K, Pinchoff J, Tidwell JB, White C, Abuya T et al. COVID19 related knowledge, attitudes, practices and needs of households in informal settlements in Nairobi, Kenya. The Lancet Global Health. 2020.

[10] Cao Z, Zhang Q, Lu X, Pfeiffer D, Jia Z, Song H, Zeng DD. Estimating the effective reproduction number of the $2019-\mathrm{nCoV}$ in China. MedRxiv. 2020.

[11] Li JY, You Z, Wang Q, Zhou ZJ, Qiu Y, Luo R, Ge XY. The epidemic of 2019-novel-coronavirus (2019-nCoV) pneumonia and insights for emerging infectious diseases in the future. Microbes and infection. 2020; 22(2):80-5.

[12] Department of health, Republic of South Africa, National COVID-19 daily report. Available on https:/www.nicd.ac.za/contact-us/ accessed on 18 February 2021.

[13] Zhong, B. L., Luo, W., Li, H. M., et al. (2020). Knowledge, attitudes, and practices towards COVID-19 among Chinese residents during the rapid rise period of the COVID-19 outbreak: A quick online crosssectional survey. International Journal of Biological Sciences, 16(10), 1745-1752.

[14] Wolf M, Serper M, Opsasnick L, et al. Awareness, attitudes, and actions related to COVID-19 among adults with chronic conditions at the onset of the US outbreak: A crosssectional survey. Annals of Internal Medicine 2020.

[15] Zhong B, Luo W, Li H, et al. Knowledge, attitudes, and practices towards COVID-19 among Chinese residents during the rapid rise period of the COVID-19 outbreak: a quick online cross-sectional survey. Int J Biol Sci 2020; 16(10): 1745-52.

[16] Ajilore K, Atakiti I, Onyenankey K. College students' knowledge, attitudes and adherence to public service announcements on Ebola in Nigeria: Suggestions for improving future Ebola prevention education programmes. Health Education Journal. 2017; 76: 648-60.

[17] Tachfouti N, Slama K, Berraho M, Nejjari C. The impact of knowledge and attitudes on adherence to tuberculosis treatment: a case-control study in a Moroccan region. Pan Afr Med J. 2012; 12: 52.

[18] Hoque AM, Alam AM, Hoque M, Hoque ME and Van Hal G. Knowledge, Attitudes, and Practices towards COVID-19 of Pregnant Women at a Primary Health Care Facility in South Africa. Euro Jour of Med and Health science 2021; 3 (1) 50-55. DOI: 10.24018/ejmed.2021.3.1.654.

[19] Hoque AM._Buckus S, Hoque M, Hoque ME. Knowledge, Attitudes $\&$ Practices of Primary Healthcare Workers on COVID-19 from a
Rural Setting of KwaZulu-Natal, South Africa. Clinical and Experimental Investigations. $\quad$ ISSN $2674-5054$ doi:10.31487/j.CEI.2020.03.0

[20] Van Walbeek C, Filby S, Van der Zee K. Smoking and Quitting Behaviour in Lockdown South Africa: Results from A Second Survey. July 2020. Research Unit on the Economics of Excisable Products. University of Cape Town. Available from www.reep.uct.ac.za/news.

[21] Al-Hanawi MK, Angawi K, Alshareef N, Qattan AM, Helmy HZ, Abudawood Y, Alqurashi M, Kattan WM, Kadasah NA, Chirwa GC, Alsharqi O. Knowledge, Attitude and Practice Toward COVID-19 Among the Public in the Kingdom of Saudi Arabia: A Cross-Sectional Study. Frontiers in Public Health. 2020;8, 217.

[22] Anikwe CC, Ogah CO, Anikwe IH, Okorochukwu BC, Ikeoha CC. Coronavirus disease 2019: Knowledge, attitude, and practice of pregnant women in a tertiary hospital in Abakaliki, southeast Nigeria. International Journal of Gynecology \& Obstetrics. 2020; 151 (2)197202.

[23] Zhou, Minghe, Tang, Fang \& Wang, Yunjian et al. Knowledge, attitude and practice regarding COVID-19 among health care workers in Henan, China. Journal of Hospital Infection. 2020; 105 (10) 101 106.

[24] Edet CK, Captain Elechi Amadi CE, Kiri VA. Knowledge, Attitude and Practice of Clients towards COVID-19 at Primary Healthcare Facilities in Rivers State, Nigeria. Research Square 2020 DOI: 10.21203/rs.3.rs-40966/v1.

[25] [25] Bekele D, Tolossa T, Tsegaye R, Teshome W. The knowledge and practice towards COVID-19 pandemic prevention among residents of Ethiopia. An online cross-sectional study. BioRxiv. 2020.

[26] Nwafor JI, Aniukwu JK, Anozie BO, Ikeotuonye AC. Knowledge and practice of preventive measures against COVID-19 infection among pregnant women in a low-resource African setting. medRxiv. 2020.

[27] Reuben RC, Danladi MM, Saleh DA, Ejembi PE. Knowledge, attitudes and practices towards COVID-19: an epidemiological survey in North-Central Nigeria. J Community Health. 2020; 1-4.

[28] Akalu Y, Ayelign B, Molla MD. Knowledge, attitude and practice towards COVID-19 among chronic disease patients at Addis Zemen Hospital, Northwest Ethiopia. Infect Drug Resist. 2020;13:1949-1960.

[29] Rugarabamu, S., Byanaku, A., Ibrahim, M. Knowledge, attitudes and practices (KAP) towards COVID-19: A quick online cross-sectional survey among Tanzanian residents. medRxiv. 2020.

[30] Azlan AA, Hamzah MR, Sern TJ, Ayub SH, Mohamad E (2020) Public knowledge, attitudes and practices towards COVID-19: A cross-sectional study in Malaysia. PLOS ONE 15(5): 233-238.

[31] Zhong B, Luo W, Li H, Zhang Q, Liu X, Li W, et al. Knowledge, attitudes and practices towards COVID-19 among Chinese residents during a rapid rise period of the COVID-19 outbreak: a quick online cross-sectional survey. Int J Biol Sci. 2020;16:1745-1752.

[32] Ferdous MZ, Islam MS, Sikder MT, et al. (2020) Knowledge, attitude and practice regarding COVID-19 outbreak in Bangladesh: An onlinebased cross-sectional study. PLos ONE 15(10): 239-254.

[33] Lau L, Hung N, Go J, et al. Knowledge, attitudes and practices among income-poor households in the Philippines: A cross-sectional study. J Glob Health. 2020;(10)1: 110-117. 